\title{
Effect of moderate magnesium deficiency on serum lipids, blood pressure and cardiovascular reactivity in normotensive rats
}

\author{
BY CATHERINE LUTHRINGER*, YVES RAYSSIGUIER †, \\ ELYETT GUEUX AND ALAIN BERTHELOT* \\ Institut National de la Recherche Agronomique, Theix 63122 Ceyrat, France
}

(Received 31 March 1987 - Accepted 6 October 1987)

\begin{abstract}
1. Weanling Wistar rats were pair fed for 10 weeks on a purified diet containing either normal or suboptimal quantities of magnesium ( 960 or $80 \mathrm{mg} / \mathrm{kg}$ respectively).

2. At week 2, hypomagnesaemia was accompanied by hypertriglyceridaemia, an increase in plasma cholesterol and a decrease in high-density-lipoprotein-cholesterol in animals fed on the Mg-deficient diet. At week 10, the increase in triglycerides observed in Mg-deficient animals was less marked while the increase in total cholesterol was more important.

3. During the whole experimental period, Mg-deficient animals never showed hypertension. At week 2 , mean arterial blood pressure was significantly lower in $\mathrm{Mg}$-deficient rats than in their respective controls, while heart rate was significantly increased. However, hypotension accompanied by tachycardia was a transitory phenomenon which appeared only in the early phase of deficiency.

4. Vascular reactivity was studied in vagotomized anaesthetized rats after ganglionic blockade with pentolinium and atropine sulphate. The reactivity to noradrenaline was significantly higher in $\mathrm{Mg}$-deficient rats compared with pair-fed controls after 2 weeks on the experimental diet.
\end{abstract}

During the past few years increased attention has been focused on the possible effect of magnesium deficiency on cardiovascular diseases (Seelig \& Heggtveit, 1974; Altura \& Altura, 1985; Rayssiguier \& Gueux, 1986). Schroeder (1960) found that hard-water areas had lower rates of vascular diseases. $\mathrm{Mg}$ may be the protective factor since drinking water can be an important dietary source of $\mathrm{Mg}$ (Marier \& Neri, 1985). The possibility that $\mathrm{Mg}$ deficiency could contribute to the development of hypertension was postulated on the basis of experimental results showing that decrements of $\mathrm{Mg}$ in vitro potentiate the vasoconstricting effect of many humoral substances in vascular beds (Altura t $t$ al. 1981), that elevation of blood pressure has been reported in rats after $\mathrm{Mg}$ deficiency of long duration (Altura et al. 1984) and that disturbances in $\mathrm{Mg}$ metabolism have been observed in patients with hypertension (Resnick et al. 1984). The effects of experimental $\mathrm{Mg}$ deficiency on blood pressure have been much debated (McCarron, 1983) since blood pressure is generally lowered in rats following severe $\mathrm{Mg}$ deficiency (Cantin, 1970; Cantin \& Huet, 1973; Itokawa et al. 1974; Kimura et al. 1984; Lowrimore \& Ward, 1985). Yet, to our knowledge, no one has studied its effect on cardiovascular reactivity (CVR) in vivo.

In view of the association between $\mathrm{Mg}$ deficiency and cardiovascular disease, the implication of $\mathrm{Mg}$ in lipid metabolism has also been considered (Rayssiguier \& Gueux, 1986). Experimental studies demonstrate a consistent abnormality of lipid metabolism in Mg-deficient rats that is closely linked to vascular-disease risk (Rayssiguier et al. 1981). Other studies have demonstrated modification of fatty acid metabolism, altered platelet function and predisposition to thrombosis in the same experimental model (Rayssiguier et al. 1986).

\footnotetext{
* Present address: UER des Sciences Pharmaceutiques, Université Louis Pasteur, 67083 Strasbourg, France.

$\dagger$ For reprints.
} 
These experiments were performed with diets severely deficient in $\mathrm{Mg}$ and it seemed of interest to evaluate the effect of less-severe $\mathrm{Mg}$ deficiency on lipid metabolism. In the work reported here, we have observed the influence of moderate $\mathrm{Mg}$ deficiency on serum lipids, blood pressure and cardiovascular reactivity to noradrenaline in normotensive rats.

\section{MATERIALS AND METHODS}

Diet composition, animals and experimental design

The experiments were conducted with 114 male Wistar rats (Iffa-Credo, France), initial mean weight 63 (SE 2) g, which were reared in our laboratory and subjected to alternating $12 \mathrm{~h}$ periods of light and darkness. The rats were randomly divided into $\mathrm{Mg}$-deficient and control groups and pair-fed with the appropriate diets. Distilled water was provided ad lib. The synthetic diets contained $(\mathrm{g} / \mathrm{kg})$ : casein 200 , sucrose 705 , maize oil 50 , mineral mixture 35, vitamin mixture 10, as described previously (Rayssiguier et al. 1981). The Mg contents determined by analysis were 80 (deficient) and $960 \mathrm{mg} / \mathrm{kg}$ (control). The experimental period was arranged at different times in order to avoid repeated blood collection in the same animals. Rats were divided into five groups of twenty animals (ten controls and ten Mg-deficient rats) for blood pressure measurement and killed after 1, 2, 4, 8 and 10 weeks. CVR was determined at week 2 on an additional group of seven control and seven $\mathrm{Mg}$ deficient rats. Blood was usually taken from the aorta under pentobarbital anaesthesia and centrifuged immediately at $2000 \mathrm{~g}$ for $15 \mathrm{~min}$ at $4^{\circ}$. Plasma from heparinized blood or serum was used for mineral and lipid analysis.

\section{Blood pressure and $C V R$}

Mean arterial systolic blood pressure (MAP) and heart rate were determined by a tail-cuff method on unanaesthetized, prewarmed rats utilizing a Narco Biosystem Physiograph. For CVR study, animals were anaesthetized with an intraperitoneal injection of sodium pentobarbital $(30 \mathrm{mg} / \mathrm{kg})$. In order to minimize their spontaneous blood pressure regulation, they were pretreated with pentolinium $(25 \mathrm{mg} / \mathrm{kg}$ subcutaneously; May and Baker) and atropine sulphate $(0.25 \mathrm{mg} / \mathrm{kg}$ subcutaneously) (Berthelot \& Gairard, 1978). Two small polyethylene cannulas were implanted, one in the carotid artery for direct measurement of mean blood pressure and one in the jugular vein for drug injections. At the same time vagotomy was performed on both sides. Mean blood pressure was measured directly with a Statham 23 DB pressure probe.

CVR to noradrenaline was expressed as changes in blood pressure evoked by injection of noradrenaline at $125,250,500,1000$ and $2000 \mathrm{ng} / \mathrm{kg}$.

\section{Mineral and lipid analysis}

Plasma $\mathrm{Mg}$ and calcium levels were measured by atomic absorption spectrophotometry (Atomic Absorption Spectrophotometer Model 420; Perkin-Elmer, Norwalk, CT). The plasma samples were diluted 1:50(v/v) with a lanthanum chloride solution $(1 \mathrm{~g}$ lanthanum/ 1). Inorganic phosphorus was estimated colorimetrically (Kalckar, 1947), and triglycerides (Bucolo \& David, 1973), total cholesterol (Allain et al. 1974) and high-density-lipoprotein (HDL)-cholesterol (Grove, 1979) were determined in serum by enzymic methods.

\section{Statistical analysis}

Results were expressed as means with their standard errors. The statistical significance of differences between means was assessed by Student's $t$ test using group analysis. 


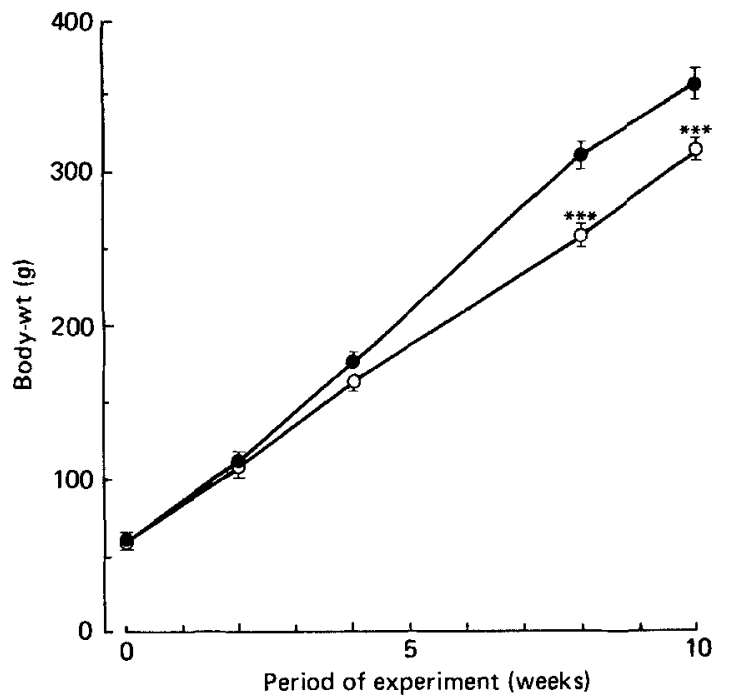

Fig. 1. Body-weights of rats fed on a control (O) or magnesium-deficient (O) diet (for details, see p. 244) for 10 weeks. Values are means, with their standard errors represented by vertical bars, for ten animals per group. Mean values were significantly different from those for the control group: *** $P<0.001$.

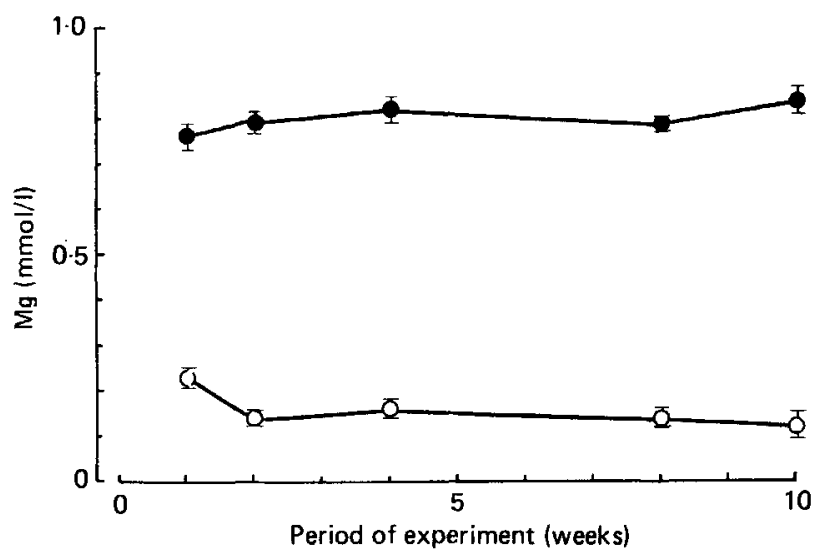

Fig. 2. Plasma magnesium levels of control ( $)$ and $\mathrm{Mg}$-deficient $(O)$ rats (for details of diets, see p. 244). Values are means, with their standard errors represented by vertical bars, for ten animals per group. Mean values were significantly different from those for the control group $(P<0.001$ for all values).

\section{RESULTS}

\section{Mg deficiency and blood lipids}

The clinical symptoms of $\mathrm{Mg}$ deficiency were observed. Hyperaemia of the ears manifested during the first 3 weeks of deficiency, reached a peak and then abruptly disappeared. Alopecia and ulcerations of the skin were also observed and disappeared after the initial 8 weeks but $\mathrm{Mg}$-deficient rats were notably hyperexcitable. Daily weight gain was similar in $\mathrm{Mg}$-deficient and pair-fed control rats during the first 4 weeks (Fig. 1). At weeks 8 and 10, $\mathrm{Mg}$-deficient rats showed significant growth retardation. Plasma Mg concentration fell rapidly during the first 2 weeks of deficiency and then stabilized (Fig. 2). At week 2, 
Table 1. Concentrations of plasma minerals ( $m M)$ in rats fed on a control or magnesiumdeficient $\uparrow$ diet for 2 weeks

(Mean values with their standard errors for ten rats/group)

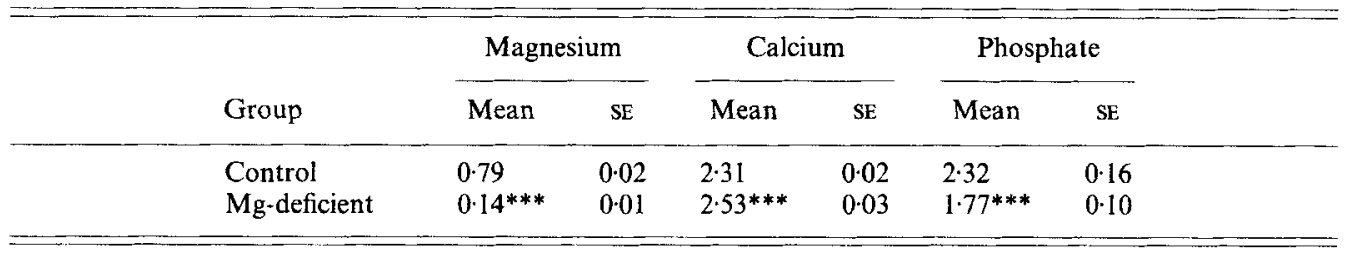

Mean values were significantly different from those of the control group: ${ }^{* * *} P<0.001$.

$\dagger$ For details, see p. 244.

Table 2. Serum lipids in rats fed on a control or magnesium-deficient $\dagger$ diet for 2 weeks

(Mean values with their standard errors for ten rats/group)

\begin{tabular}{|c|c|c|c|c|c|c|c|c|}
\hline \multirow[b]{2}{*}{ Group } & \multicolumn{2}{|c|}{$\begin{array}{l}\text { Triglycerides } \\
\text { (mM) }\end{array}$} & \multicolumn{2}{|c|}{$\begin{array}{l}\text { Total } \\
\text { cholesterol } \\
(\mathrm{mM})\end{array}$} & \multicolumn{2}{|c|}{$\begin{array}{l}\text { HDL-cholesterol } \\
\text { (mM) }\end{array}$} & \multicolumn{2}{|c|}{$\begin{array}{l}\text { HDL-cholesterol } \\
\text { total cholesterol } \\
(\mathrm{mmol} / \mathrm{mol})\end{array}$} \\
\hline & Mean & SE & Mean & $\mathrm{SE}$ & Mean & $\mathrm{SE}$ & Mean & $\mathrm{SE}$ \\
\hline Control & 0.84 & $0 \cdot 19$ & $1 \cdot 23$ & 0.08 & $0 \cdot 81$ & 0.07 & 660 & 30 \\
\hline Mg-deficient & $4 \cdot 70^{* * *}$ & 0.52 & $1.72 *$ & 0.17 & $0 \cdot 31 * * *$ & 0.02 & $190^{* * *}$ & 20 \\
\hline
\end{tabular}

HDL, high-density-lipoprotein.

Mean values were significantly different from those for the control group: ${ }^{*} P<0.05, * * * P<0 \cdot 001$.

$\dagger$ For details, see p. 244.

Table 3. Serum lipids in rats fed on a control or magnesium-deficient $\dagger$ diet for 10 weeks (Mean values with their standard errors for ten rats/group)

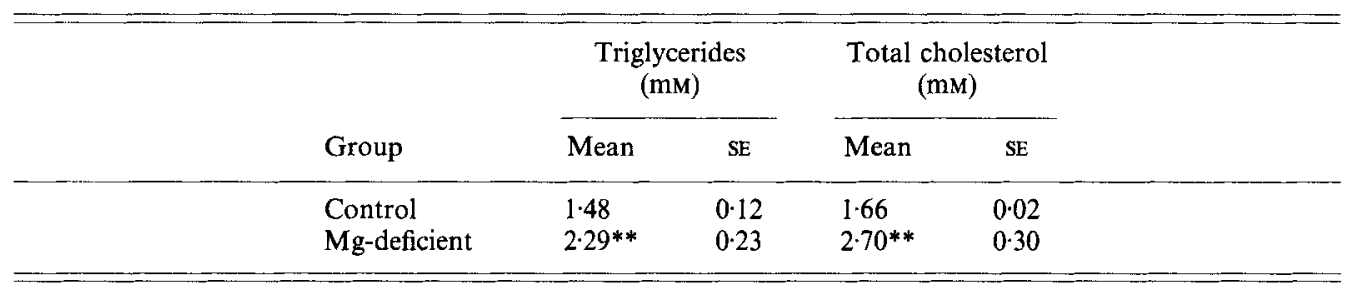

Mean values were significantly different from those for the control group: ${ }^{* *} P<0.01$.

$\dagger$ For details, see p. 244.

hypomagnesaemia was accompanied by a moderate increase in $\mathrm{Ca}$ concentration and hypophosphataemia (Table 1) and hyperlipidaemia (Table 2). The increase in triglycerides was observed with a low increase in total cholesterol. The level of HDL-cholesterol decreased as well as the HDL-cholesterol :total cholesterol ratio. At week 10, increase in triglycerides and cholesterol levels persisted but the characteristics of hyperlipidaemia were different from those observed at week 2 . The increase in triglycerides observed in $\mathrm{Mg}$ deficient animals compared with pair-fed controls was less marked while the increase in cholesterol was more important (Table 3). 


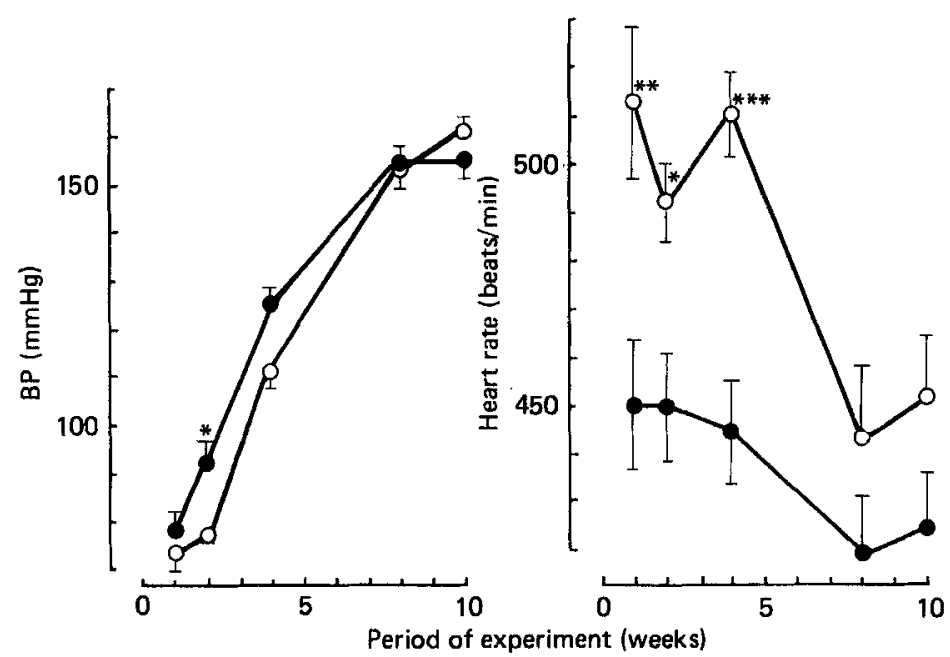

Fig. 3. Blood pressure (BP) and heart rate in control $(O)$ and magnesium-deficient $(O)$ rats (for details of diets, see p. 244). Values are means, with their standard errors represented by vertical bars, for ten animals per group. Mean values were significantly different from those for the control group: ${ }^{*} P<0 \cdot 05$, ${ }^{* *} P<0.01,{ }^{* * *} P<0.001$.

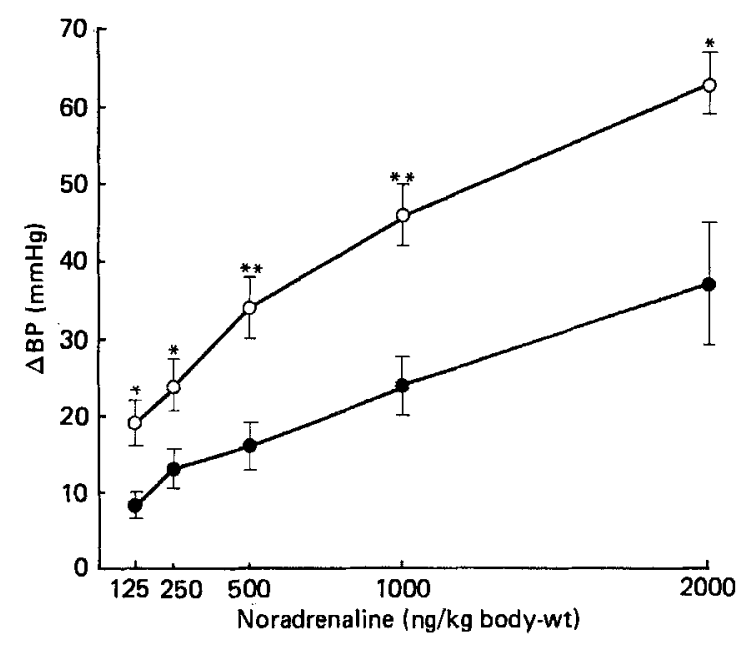

Fig. 4. Cardiovascular reactivity (CVR) to noradrenaline in rats fed on control (O) or magnesiumdeficient (O) diets for 2 weeks (for details, see p. 244). CVR is expressed as the change in blood pressure $(\triangle B P)$ after injection of one of five doses of noradrenaline $(125,250,500,1000$ and $2000 \mathrm{ng} / \mathrm{kg})$. Values are means, with their standard errors represented by vertical bars, for seven animals per group. Mean values were significantly different from those for the control group: ${ }^{*} P<0.05,{ }^{* *} P<0.01$.

\section{Blood pressure and $C V R$}

MAP was lower in Mg-deficient animals than their respective controls during the first 4 weeks of deficiency; however, this difference was only significant at week 2 . This hypotensive tendency and tachycardia observed during the initial period disappeared after the 4 th week of deficiency (Fig. 3).

Fig. 4 shows the pressor response to noradrenaline obtained in control and $\mathrm{Mg}$-deficient rats. The increase of MAP in Mg-deficient rats was significantly higher than similar responses obtained in control rats for all doses of noradrenaline administered. 
DISCUSSION

The present study establishes that moderate $\mathrm{Mg}$ deficiency affects lipid metabolism and transitorily decreases blood pressure in normotensive rats. In addition this investigation provides what is believed to be the first direct evidence that $\mathrm{Mg}$ deficiency increases CVR in the living animal. The effectiveness of the diet used to induce $\mathrm{Mg}$ deficiency was clearly shown by the usual depression in plasma $\mathrm{Mg}$ as well as the clinical manifestation of the syndrome (Cantin, 1970). Mg deficiency results in a decreased efficiency of food utilization and the lower body-weight of Mg-deficient rats compared with pair-fed controls has been reported repeatedly (e.g. Cantin, 1970). The biochemical findings of the present experiment essentially confirm earlier findings from Mg-deficient states. In rats, the development of $\mathrm{Mg}$ deficiency resulted in a drop in plasma $\mathrm{Mg}$ level followed by hypophosphataemia and a moderate increase in Ca concentration (Rayssiguier et al. 1982).

Previous experiments have shown that severe $\mathrm{Mg}$ deficiency in weanling rats resulted in marked changes in lipid metabolism (Rayssiguier et al. 1981). The most pronounced effect of the Mg-deficient diet was on plasma triglycerides. While the level of total cholesterol remained unchanged, the proportion of esterified cholesterol was decreased. Cholesterol levels increased in the very-low-density-lipoprotein and low-density-lipoprotein fractions, and decreased in the HDL fraction. Hypertriglyceridaemia was the consequence of a decreased clearance of lipids. A marked reduction in plasma activity of phosphatidylcholine-sterol acyltransferase (lecithin cholesterol acyltransferase; $E C 2.3 .1 .43$ ) may explain the decrease in esterification of cholesterol and contribute to the impaired transport and disposal of triglycerides (Rayssiguier \& Gueux, 1983; Gueux et al. 1984). These previous experiments were performed with diets severely deficient in $\mathrm{Mg}(35 \mathrm{mg} / \mathrm{kg}$ ) which, because of the severity of the deficiency, could not be used for a long period. The present experiment has been conducted with the same purified diet but less severely deficient in $\mathrm{Mg}$. This allows for longer maintenance of deficient animals without mortality. The results of the present experiment indicate that moderate $\mathrm{Mg}$ deficiency for 2 weeks induces modifications of lipid metabolism similar to those previously observed with severe deficiency. However, hypertriglyceridaemia appears to be less intense in the long-term, 10week experiment. In contrast to the slight modification of total cholesterol in severe $\mathrm{Mg}$ deficiency of short duration, there was a significant increase in total cholesterol during moderate $\mathrm{Mg}$-deficiency of long duration. The origin of the adaptation of lipid metabolism in prolonged deficiency remains to be elucidated.

The observation of hypotension agrees with previous results in $\mathrm{Mg}$-deficient rats (Cantin, 1970; Cantin \& Huet, 1973; Itokawa et al. 1974; Kimura et al. 1984; Lowrimore \& Ward, 1985). The present experiment, however, indicates that hypotension is a transitory phenomenon which appears only in the early phase of moderate $\mathrm{Mg}$ deficiency and might be overlooked in experiments where MAP is only measured after a long period of deficiency (Altura et al. 1984). The higher heart rate observed in Mg-deficient animals seems to be the consequence of regulatory controls induced by hypotension, since heart rate modification diminished soon after the disappearance of hypotension. Growth impairment of $\mathrm{Mg}$ deficient animals cannot explain the hypotensive effect which was observed in the early stage of deficiency when body-weights of pair-fed control and deficient animals were similar. In the absence of heart rate modification, hypotension is still observed in $\mathrm{Mg}$ deficient rats when voluntary, sympathetic and parasympathetic influences on blood pressure and heart rate are pharmacoligically inhibited (Lowrimore \& Ward, 1985). This suggests that peripheral regulations are not involved in blood-pressure modifications.

The fact that arterial blood pressure was identical in control and $\mathrm{Mg}$-deficient animals after the initial phase of deficiency suggests that hypotension is an indirect consequence of 
$\mathrm{Mg}$ deficiency and not the consequence of the drop in plasma $\mathrm{Mg}$. The hypotension in the Mg-deficient animals could have several causes. $\mathrm{Mg}$ deficiency is accompanied by disturbances in metabolism of $\mathrm{Ca}$ and $\mathrm{P}$ (Rayssiguier et al. 1982). Dietary $\mathrm{P}$ deficiency induces hypophosphataemia and hypotension in normotensive Sprague Dawley rats (Campese et al. 1984). Disturbances in $\mathrm{P}$ metabolism could then contribute to the hypotensive effect of $\mathrm{Mg}$ deficiency. During the early weeks of deficiency, hypotension may also be due to the release of histamine that is implicated in generalized hyperaemia (Cantin, 1970; Bois et al. 1963). However, concerning Ca metabolism (Rayssiguier et al. 1982) and histamine liberation (Miyao et al. 1984) the response to $\mathrm{Mg}$ deficiency in the rat is not the same as in other species and it would be of interest to determine whether other species similarly develop hypotension during $\mathrm{Mg}$ deficiency.

The increase in blood pressure after noradrenaline injection corresponds to the intrinsic response of the cardiovascular system, since this effect was observed in rats after abolition of the ability to regulate cardiac and vascular activities. Since there are no variation of heart rate after stimulation by noradrenaline, it seems possible that the increase in blood pressure would be the consequence of a modification in vascular response.

In the context of cardiovascular disease, the major question is to determine whether $\mathrm{Mg}$ deficiency could be a hypertensive factor in particular conditions as previously suggested (Schroeder, 1960; Altura et al. 1981, 1984; Altura \& Altura, 1985; Marier \& Neri, 1985). Our findings concerning CVR to noradrenaline in vivo are of particular significance precisely because catecholamines play an important role during stress conditions. Thus, an increased sensitivity of the cardiovascular system to noradrenaline in rats under stress conditions and $\mathrm{Mg}$ deficiency may be a possible explanation for the development of hypertension, as observed previously by others (Altura et al. 1981, 1984; Altura \& Altura, 1985).

Results of the present experiment agree with experimental findings obtained in vitro where either removal of $\mathrm{Mg}$ from the external medium or lowering of $\mathrm{Mg}$ concentration enhanced the reactivity of small and large coronary vessels to catecholamines, angiotensin II, serotonin, acetylcholine and vasoactive peptides (Altura et al. 1981; Altura \& Altura, 1985). Other in vitro studies suggested that in vascular muscles, $\mathrm{Mg}$ can act physiologically to control and regulate entry and exit of Ca (Altura et al. 1981; Altura \& Altura, 1985). Since catecholamines utilize Ca to elicit contractile responses (Godfraind \& Kaba, 1972; Bohr, 1973; Blaustein, 1.977), the observed alteration of CVR in Mg-deficient rats may reflect alterations in cellular $\mathrm{Ca}$ availability.

The present findings demonstrate that moderate $\mathrm{Mg}$ deficiency in rats induces abnormal lipid metabolism, transitory hypotension and increase in CVR to noradrenaline. While $\mathrm{Mg}$ depletion has been documented in man in various nutritional or pathological conditions (Seelig, 1980; Rayssiguier et al. 1982; Durlach, 1985), further studies are required to clarify the complex relations between $\mathrm{Mg}$, lipid metabolism and blood pressure in connection with cardiovascular diseases.

\section{REFERENCES}

Allain, C. C., Poon, L. S., Chan, C. S. G., Richemon, W. \& Fu, P. C. (1974), Clinical Chemistry $20,470-475$. Altura, B. M. \& Altura, B. T. (1985). Magnesium 4, 226-271.

Altura, B. M., Altura, B. G., Carella, A. \& Turlapaty, P. D. M. V. (1981). Artery 9, 212-231.

Altura, B. M., Altura, B. T., Gebrewold, A., Ising, H. \& Gunther, T. (1984). Science 223, 1315-1317.

Berthelot, A. \& Gairard, A. (1978). British Journal of Pharmacology 62, 119-205.

Blaustein, M. (1977). American Journal of Physiology 132, C165-C171.

Bois, P., Gascon, A. \& Beaulnes, A. (1963). Nature 197, 501-503.

Bohr, D. F. (1973). Circulation Research 32, 665-672.

Bucolo, G. \& David, H. (1973). Clinical Chemistry 19, 476-482. 
Campese, V. M., Saglikes, Y., Iseki, K. \& Massry, S. G. (1984). Advances in Experimental Medicine and Biology 178, 271-274.

Cantin, M. (1970). Laboratory Investigation 22, 558-568.

Cantin, M. \& Huet, M. (1973). Canadian Journal of Physiology and Pharmacology 51, 835-844.

Durlach, J. (editor) (1985). Le Magnesium en Pratique Clinique. Paris: J. B. Ballière.

Godfraind, T. \& Kaba, A. (1972). Archives Internationales de Pharmacodynamie et de Thérapie 196, 35-49.

Grove, T. H. (1979). Clinical Chemistry 25, 560-564.

Gueux, E., Rayssiguier, Y., Piot, M. C. \& Alcindor, L. (1984). Journal of Nutrition 114, 1479-1483.

Itokawa, Y., Tanaka, C. \& Fujiwara, M. J. (1974). Journal of Applied Physiology 7, 835-839.

Kalckar, H. M. (1947). Journal of Biological Chemistry 167, 477-486.

Kimura, M., Harada, T. \& Itokawa, Y. (1984). Magnesium Bulletin 3, 125.

Lowrimore, P. \& Ward, J. A. (1985). Journal of the American College of Nutrition 4, 381.

Marier, J. R. \& Neri, L. C. (1985). Magnesium 4, 53-59.

McCarron, D. A. (1983). Annals of Internal Medicine 98, 800-805.

Miyao, N., Ikegaki, I., Nishio, A. \& Ishiguro, S. (1984). Memoirs of the Faculty Agriculture, Kagoshima University 20, 111-125.

Rayssiguier, Y. \& Gueux, E. (1983), Magnesium 2, 132-138.

Rayssiguier, Y. \& Gueux, E. (1986). Journal of American College of Nutrition 5, 507-519.

Rayssiguier, Y., Gueux, E., Cardot, P., Thomas, G., Robert, A. \& Trugnan, G. (1986). Nutrition Research 6, 233-240.

Rayssiguier, Y., Gueux, E. \& Weiser, D. (1981). Journal of Nutrition 111, 1876-1883.

Rayssiguier, Y., Thomasset, M., Garel, J. M. \& Barlet, J. P. (1982). Hormone and Metabolic Research 14, 379--382.

Resnick, L. M., Gupta, R. K. \& Laragh, J. H. (1984). Proceedings of the National Academy of Sciences USA 81, 6511-6515.

Schroeder, H. A. (1960). Journal of the American Medical Association 172, 1902-1908.

Seelig, M. S. (editor) (1980). Magnesium Deficiency in the Pathogenesis of Disease. New York and London: Plenum Medical Book.

Seelig, M. S. \& Heggtveit, H. A. (1974). American Journal of Clinical Nutrition 27, 59-79. 